\title{
Preparation of Pineapple (Ananas comosus) Candy Using Osmotic Dehydration Combined With Solar Drying
}

\author{
Sultana Anjuman Ara Khanom¹, Md. Mashiar Rahman² and M. Burhan Uddin ${ }^{3 *}$ \\ ${ }^{I}$ Vegetable Technology Research Section, Institute of Food Science \& Technology, BCSIR, Dhaka- \\ 1205; ${ }^{2}$ Enzymology Section, Institute of Food Science \& Technology, BCSIR, Dhaka-1205; \\ ${ }^{3}$ Department of Food Technology and Rural Industries, Bangladesh Agricultural University, \\ Mymensigh-2202, Bangladesh \\ *Corresponding author and Email: burhan.ftri@bau.edu.bd
}

Received: 21 July $2014 \quad$ Accepted: 06 June 2015

\begin{abstract}
This study was conducted to develop pineapple candy prepared from fresh pineapple using 40, 50 and $60 \%$ sugar solution and then dried in solar drier. Acceptability of the product was also assessed. The thickness of pineapple slices were 0.5 and $1.0 \mathrm{~cm}$. The pineapple slices were dipped into $40,50 \& 60 \%$ sugar solutions for overnight and then dried in solar drier. It was found that $0.5 \mathrm{~cm}$ thick of pineapple slices dried quickly than $1 \mathrm{~cm}$ thick slices. Sensory quality attributes of the prepared pineapple candy were analysed on the basis of colour, flvour, texture and overal acceptability using ANOVA test followed by DMRT test for identification of the best pineapple candy. Samples having $0.5 \mathrm{~cm}$ slice, osmosed in $60 \%$ sugar solution and $0.5 \mathrm{~cm}$ slice, osmosed in $50 \%$ sugar solution were the preferred samples with respect to quality attributes and ranked as "like very much". The samples having $0.5 \mathrm{~cm}$ slice, osmosed in $60 \%$ sugar solution was the most acceptable among candies prepared under the study.
\end{abstract}

Keywords: Osmotic dehydration, pineapple candy, solar drying

\section{Introduction}

Pineapple (Ananas comosus) is a tropical fruit which grows well in the tropical and sub-tropical regions. It is native to Central and South America. Pineapple belongs to the Bromeliaceae family and grows on the ground. Pineapple is a popular fruit of Bangladesh. Preliminary experiments on osmotic dehydration of pineapple carried out by Shahabuddin et al. (1990) have shown that solutions with less than $40 \%$ sugar content are not very effective for osmosis. Increasing sugar concentration in dehydration solutions has the effect of stimulating water loss while hindering sugar gain
(Heng et al., 1990). Concentrated sucrose solutions $\left(50-75^{\circ}\right.$ Brix) have been most commonly used (Kim et al., 1987). Lenart and Flink (1984a) found that water loss and total solids in potato were directly proportional to the initial concentration of the sucrose in solution over the range $20-70$ per cent. The present work was undertaken to prepare pineapple candy from fresh pineapple and to assess the acceptability of the pineapple candy.

\section{Materials and Methods}

The experiment was conducted in the department of Food Technology and Rural Industries, BAU, 
Mymensingh. The pineapples, having a maturity index between M1 and M2 (10-30\% colouration from base) and sugar were collected from a local market. Apparatus used were electric balance, knives, solar dryer, digital moisture meter, and stainless steel pan.

\subsection{Preparation of samples}

Well matured, firm and ripe medium-sized pineapples (Ananas comosus) were washed thoroughly in water, outer skin was peeled manually by knife, cut into pieces of 0.5 and $1.0 \mathrm{~cm}$ thickness. The core of the slices was also removed using core remover. The descriptions of samples are given in Table 1.

\subsection{Dehydration of candy}

The dehydration solute used was sucrose (food grade) sugar manufactured. Solutions of 40, $50 \%$ and $60 \%(\mathrm{w} / \mathrm{w})$ sucrose concentrations were prepared by blending an amount of sucrose with distilled water on a weight to weight basis. The pineapple slices of different thickness were dipped in different concentrations of sugar solution kept in stainless steel pan and were boiled for 30 minutes and then kept at room temperature for overnight. In the preparation of pineapple candy osmotic dehydration step prior to drying was used as described by Ramamurthey et al. (1970).

After osmosis, the pieces of pineapple from different sugar solution was removed, drained and then dried in solar dryer at temperature of $55 \pm 5^{\circ} \mathrm{C}$ for $5-14$ hours. The direct absorption type solar dryer was used in this research . The dryer consisted of a box with single transparent cover (polythene) and blackend interior surface. The pineapple slices $(0.5 \& 1 \mathrm{~cm})$ in trays were directly exposed in the dryer in which the solar radiation is transmitted through transparent polythene into dryer box and absorbed by the black surfaces of the dryer and converted into heat. To facilitate air circulation, ventilation holes were made at the front side and at the back side of the dryer. Moisture from the slices was evaporated by the heat. The heat also causes circulation of the air which removes the evaporated moisture.

\subsection{Storage studies}

The dehydrated samples packaged in high density polyethylene were stored at room temperature $\left(27\right.$ to $\left.32{ }^{\circ} \mathrm{C}\right)$ for a period of 240 days. The changes in colour, flavour, and moisture content, fungal growth and overall acceptability were observed.

\subsection{Sensory evaluation}

Sensory evaluation of stored osmosed pineapple samples were carried out in sensory panel laboratory and sensory attributes were tested. A total of 10 panelists, ranging in age from 20-40 years, who were students and staff of the Department of Food Technology and Rural Industries, BAU, Mymensingh participated in this study. Samples were evaluated in a soundproof, humidity-controlled sensory room with individual booths.

Table 1. Description of the samples of pineapple slices

\begin{tabular}{cccc}
\hline Sample no. & Type & Thickness of slice $(\mathrm{cm})$ & $\begin{array}{c}\text { Concentration of sugar } \\
\text { solution (\% sugar) }\end{array}$ \\
\hline $\mathrm{S}_{1}$ & Fresh & 0.5 & - \\
$\mathrm{S}_{2}$ & Fresh & 1 & - \\
$\mathrm{S}_{3}$ & Osmosed & 0.5 & 40 \\
$\mathrm{~S}_{4}$ & Osmosed & 1 & 40 \\
$\mathrm{~S}_{5}$ & Osmosed & 0.5 & 50 \\
$\mathrm{~S}_{6}$ & Osmosed & 1 & 50 \\
$\mathrm{~S}_{7}$ & Osmosed & 0.5 & 60 \\
$\mathrm{~S}_{8}$ & Osmosed & 1 & 60 \\
\hline
\end{tabular}


Incandescent lighting was used to mask any colour differences that might have influenced a panelist's judgment. Evaluations were held once a day in the mid-afternoon, three times a week during the whole storage period. A total of three replications were completed. The products were served to each judge who independently examined the colour, flovour, texture and overall acceptability. The hedonic rating test was used to measure the consumers acceptability of the product; and the relevant importance of each factor was compared numerically on a scale of 1 to 9 .

\section{Results and Discussion}

\subsection{Effect of thickness on drying rate constant of fresh and osmosed pineapple}

The $0.5 \mathrm{~cm}$ and $1 \mathrm{~cm}$ thick pineapple slices were dried at $60{ }^{\circ} \mathrm{C}$ and data were analyzed and drying rate constant was determined by plotting moisture ratio (MR) against time as shown in Figure 1 and given in Table 2. The drying rate

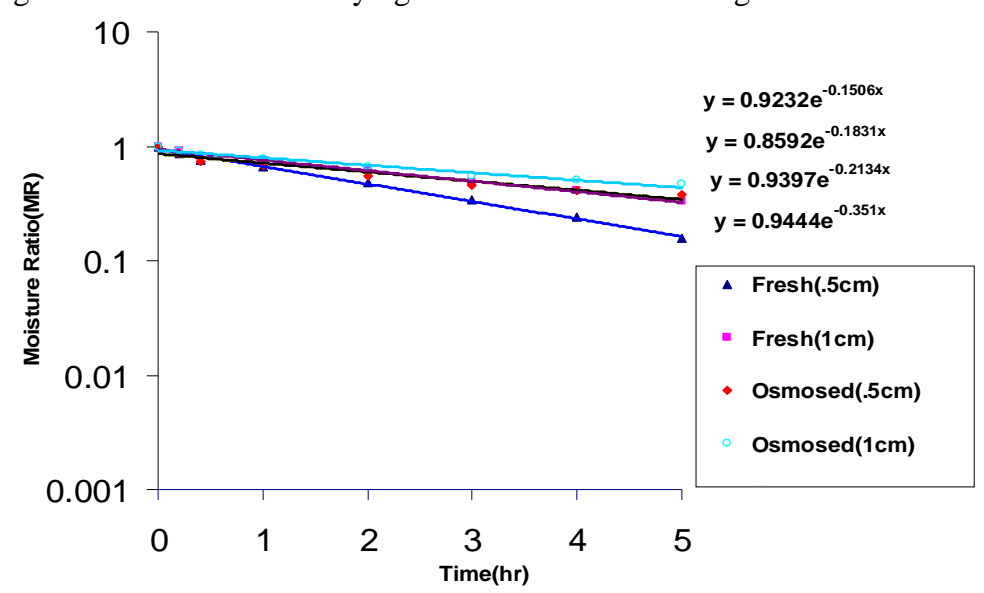

Figure 1. Comparison of drying rate constant of fresh and osmosed pineapple slices

Table 2. Drying rate constant of fresh and osmosed pineapple slices for $0.5 \mathrm{~cm}$ and $1.0 \mathrm{~cm}$ thickness

\begin{tabular}{lccc}
\hline $\begin{array}{c}\text { Sample } \\
\text { Type }\end{array}$ & $\begin{array}{c}\text { Sample Thickness } \\
(\mathrm{cm})\end{array}$ & Temperature $\left({ }^{\circ} \mathrm{C}\right)$ & $\begin{array}{c}\text { Drying Rate Constant } \\
\text { per hour }\end{array}$ \\
\hline Fresh & 0.5 & 60 & -0.315 \\
Fresh & 1 & 60 & -0.2134 \\
Osmosed & 0.5 & 60 & -0.1831 \\
Osmosed & 1 & 60 & -0.1506 \\
\hline
\end{tabular}

constant of fresh samples were higher than the osmosed samples. It is also observed that the drying rate constant decreased with increased thickness.

\subsection{Effect of solar drying on fresh and osmosed pineapple slices for different thickness}

The pineapple slices of 0.5 and $1.0 \mathrm{~cm}$ thickness were dried in solar dryer at $60 \pm 2{ }^{\circ} \mathrm{C}$ for $9-15$ hours to obtain constant weight. The fresh samples took more time to obtain constant weight than the osmosed sample and also $0.5 \mathrm{~cm}$ thick slices took less time than $1.0 \mathrm{~cm}$ thick slices. The samples were dried to a final moisture content of $27.25 \%$ (Table 3 ).

\subsection{Shelf-life studies}

Table 4 shows that there was slight gradual increase in moisture with the storage time. The candy samples were found shelf-stable at room temperature of 27 to $32^{\circ} \mathrm{C}$ for upto 7 (seven) months of storage. 
Table 3. Comparison of time required to obtain constant weight of slices

\begin{tabular}{lcccc}
\hline Sample & Thickness & $\begin{array}{c}\text { Initial moister } \\
\text { content } \\
(\% \mathrm{mc} \mathrm{wb})\end{array}$ & $\begin{array}{c}\text { Drying time (hr) to } \\
\text { obtain constant } \\
\text { weight }\end{array}$ & $\begin{array}{c}\text { Final moisture } \\
\text { content } \\
(\% \text { mc wb) }\end{array}$ \\
\hline Fresh & 0.5 & 86.45 & 13 & 27.20 \\
Osmosed & 1.0 & 86.45 & 15 & 27.27 \\
(40\%) syrup & 0.5 & 57.52 & 11 & 27.25 \\
Osmosed & 1.0 & 66.78 & 14 & 27.19 \\
(50\%) syrup & 0.5 & 48.80 & 10 & 27.22 \\
Osmosed & 1.0 & 54.14 & 13 & 27.17 \\
(60\%) syrup & 0.5 & 46.87 & 9 & 27.24 \\
\hline
\end{tabular}

Table 4 . Storage studies on pineapple candy at room temperature

\begin{tabular}{|c|c|c|c|c|c|c|}
\hline \multirow{2}{*}{$\begin{array}{c}\text { Duration } \\
\text { days }\end{array}$} & \multirow[t]{2}{*}{ Samples } & \multicolumn{4}{|c|}{ Observations } & \multirow[b]{2}{*}{$\begin{array}{c}\text { Overall } \\
\text { acceptability }\end{array}$} \\
\hline & & Colour & Flavour & $\begin{array}{c}\text { Moisture } \\
\%\end{array}$ & $\begin{array}{l}\text { Fungal } \\
\text { growth }\end{array}$ & \\
\hline \multirow{8}{*}{30} & $\mathrm{~S}_{1}$ & Good & Acceptable & 27.20 & Not visible & Acceptable \\
\hline & $\mathrm{S}_{2}$ & Good & Acceptable & 27.27 & Not visible & Acceptable \\
\hline & $\mathrm{S}_{3}$ & Good & Acceptable & 27.25 & Not visible & Acceptable \\
\hline & $\mathrm{S}_{4}$ & Good & Acceptable & 27.19 & Not visible & Acceptable \\
\hline & $\mathrm{S}_{5}$ & Good & Acceptable & 27.22 & Not visible & Acceptable \\
\hline & $\mathrm{S}_{6}$ & Good & Acceptable & 27.17 & Not visible & Acceptable \\
\hline & $\mathrm{S}_{7}$ & Good & Acceptable & 27.24 & Not visible & Acceptable \\
\hline & $\mathrm{S}_{8}$ & Good & Acceptable & 27.26 & Not visible & Acceptable \\
\hline \multirow{8}{*}{60} & $\mathrm{~S}_{1}$ & Good & Acceptable & 27.30 & Not visible & Acceptable \\
\hline & $\mathrm{S}_{2}$ & Good & Acceptable & 27.35 & Not visible & Acceptable \\
\hline & $\mathrm{S}_{3}$ & Good & Acceptable & 27.32 & Not visible & Acceptable \\
\hline & $\mathrm{S}_{4}$ & Good & Acceptable & 27.40 & Not visible & Acceptable \\
\hline & $\mathrm{S}_{5}$ & Good & Acceptable & 27.38 & Not visible & Acceptable \\
\hline & $\mathrm{S}_{6}$ & Good & Acceptable & 27.28 & Not visible & Acceptable \\
\hline & $\mathrm{S}_{7}$ & Good & Acceptable & 27.32 & Not visible & Acceptable \\
\hline & $\mathrm{S}_{8}$ & Good & Acceptable & 27.36 & Not visible & Acceptable \\
\hline \multirow{8}{*}{90} & $\mathrm{~S}_{1}$ & Good & Acceptable & 27.41 & Not visible & Acceptable \\
\hline & $\mathrm{S}_{2}$ & Good & Acceptable & 27.45 & Not visible & Acceptable \\
\hline & $\mathrm{S}_{3}$ & Good & Acceptable & 27.40 & Not visible & Acceptable \\
\hline & $\mathrm{S}_{4}$ & Good & Acceptable & 27.45 & Not visible & Acceptable \\
\hline & $\mathrm{S}_{5}$ & Good & Acceptable & 27.48 & Not visible & Acceptable \\
\hline & $\mathrm{S}_{6}$ & Good & Acceptable & 27.46 & Not visible & Acceptable \\
\hline & $\mathrm{S}_{7}$ & Good & Acceptable & 27.42 & Not visible & Acceptable \\
\hline & $\mathrm{S}_{8}$ & Good & Acceptable & 27.46 & Not visible & Acceptable \\
\hline
\end{tabular}


Table 4 Continued

\begin{tabular}{|c|c|c|c|c|c|c|}
\hline \multirow{2}{*}{$\begin{array}{c}\text { Duration } \\
\text { days }\end{array}$} & \multirow[t]{2}{*}{ Samples } & \multicolumn{4}{|c|}{ Observations } & \multirow[b]{2}{*}{$\begin{array}{c}\text { Overall } \\
\text { acceptability }\end{array}$} \\
\hline & & Colour & Flavour & Moisture\% & $\begin{array}{l}\text { Fungal } \\
\text { growth }\end{array}$ & \\
\hline \multirow{8}{*}{120} & $\mathrm{~S}_{1}$ & Good & Acceptable & 27.55 & Not visible & Acceptable \\
\hline & $\mathrm{S}_{2}$ & Good & Acceptable & 27.52 & Not visible & Acceptable \\
\hline & $\mathrm{S}_{3}$ & Good & Acceptable & 27.58 & Not visible & Acceptable \\
\hline & $\mathrm{S}_{4}$ & Good & Acceptable & 27.56 & Not visible & Acceptable \\
\hline & $\mathrm{S}_{5}$ & Good & Acceptable & 27.55 & Not visible & Acceptable \\
\hline & $\mathrm{S}_{6}$ & Good & Acceptable & 27.54 & Not visible & Acceptable \\
\hline & $\mathrm{S}_{7}$ & Good & Acceptable & 27.55 & Not visible & Acceptable \\
\hline & $\mathrm{S}_{8}$ & Good & Acceptable & 27.56 & Not visible & Acceptable \\
\hline \multirow{8}{*}{180} & $\mathrm{~S}_{1}$ & Good & Acceptable & 27.72 & Not visible & Acceptable \\
\hline & $\mathrm{S}_{2}$ & Good & Acceptable & 27.74 & Not visible & Acceptable \\
\hline & $\mathrm{S}_{3}$ & Good & Acceptable & 27.72 & Not visible & Acceptable \\
\hline & $\mathrm{S}_{4}$ & Good & Acceptable & 27.75 & Not visible & Acceptable \\
\hline & $\mathrm{S}_{5}$ & Good & Acceptable & 27.76 & Not visible & Acceptable \\
\hline & $\mathrm{S}_{6}$ & Good & Acceptable & 27.77 & Not visible & Acceptable \\
\hline & $\mathrm{S}_{7}$ & Good & Acceptable & 27.75 & Not visible & Acceptable \\
\hline & $\mathrm{S}_{8}$ & Good & Acceptable & 27.73 & Not visible & Acceptable \\
\hline \multirow{8}{*}{210} & $\mathrm{~S}_{1}$ & Slight change & Slight change & 27.85 & Not visible & Acceptable \\
\hline & $\mathrm{S}_{2}$ & Slight change & Slight change & 27.86 & Not visible & Acceptable \\
\hline & $\mathrm{S}_{3}$ & Slight change & Slight change & 27.88 & Not visible & Acceptable \\
\hline & $\mathrm{S}_{4}$ & Slight change & Slight change & 27.87 & Not visible & Acceptable \\
\hline & $\mathrm{S}_{5}$ & Slight change & Slight change & 27.85 & Not visible & Acceptable \\
\hline & $\mathrm{S}_{6}$ & Slight change & Slight change & 27.90 & Not visible & Acceptable \\
\hline & $\mathrm{S}_{7}$ & Slight change & Slight change & 27.91 & Not visible & Acceptable \\
\hline & $\mathrm{S}_{8}$ & Slight change & Slight change & 27.92 & Not visible & Acceptable \\
\hline \multirow{8}{*}{240} & $\mathrm{~S}_{1}$ & Change & Change & 28.67 & Visible & Not Acceptable \\
\hline & $\mathrm{S}_{2}$ & Change & Change & 28.77 & Visible & Not Acceptable \\
\hline & $\mathrm{S}_{3}$ & Change & Change & 28.75 & Visible & Not Acceptable \\
\hline & $\mathrm{S}_{4}$ & Change & Change & 28.79 & Visible & Not Acceptable \\
\hline & $\mathrm{S}_{5}$ & Change & Change & 28.76 & Visible & Not Acceptable \\
\hline & $\mathrm{S}_{6}$ & Change & Change & 28.78 & Visible & Not Acceptable \\
\hline & $\mathrm{S}_{7}$ & Change & Change & 28.80 & Visible & Not Acceptable \\
\hline & $\mathrm{S}_{8}$ & Change & Change & 28.83 & Visible & Not Acceptable \\
\hline
\end{tabular}

\subsection{Sensory evaluation of dehydrated pineapple} slices

A two way analysis of variance (ANOVA) at 5\% level of statistical significance was conducted for scores given by panelists for colour, flavour, texture and overall acceptability of dehydrated pineapple slices. The mean score for the test parameters of dehydrated pineapple slices are presented in Table 5.
The sample $\mathrm{S}_{5}$ was the most preferable. But $\mathrm{S}_{5}$ and $S_{7}$ were equally acceptable at $5 \%$ level of significance. It can be noted that sample $\mathrm{S}_{5}$ secured the highest score of 8.7 out of 9 , and $S_{7}$ secured the highest score of 8.4 points for colour and can be ranked as "like very much". The samples $\mathrm{S}_{3}, \mathrm{~S}_{4}, \mathrm{~S}_{6}$ and $\mathrm{S}_{8}$ were comparatively less acceptable securing scores of 7.7, 7.3, 7.5 and 8.0, respectively. 
Table 5. Mean score of sensory attributes of dehydrated pineapple slices

\begin{tabular}{ccccc}
\hline \multirow{2}{*}{ Product Type } & \multicolumn{4}{c}{ Sensory attributes } \\
\cline { 2 - 5 } & Colour & Flavour & Texture & Overall acceptability \\
\hline $\mathrm{S}_{1}$ & $4.80^{\mathrm{e}}$ & $5.40^{\mathrm{e}}$ & $5.40^{\mathrm{c}}$ & $5.70^{\mathrm{e}}$ \\
$\mathrm{S}_{2}$ & $4.30^{\mathrm{f}}$ & $4.70^{\mathrm{f}}$ & $5.20^{\mathrm{c}}$ & $5.00^{\mathrm{f}}$ \\
$\mathrm{S}_{3}$ & $7.70^{\mathrm{cd}}$ & $7.70^{\mathrm{bc}}$ & $7.70^{\mathrm{b}}$ & $7.70^{\mathrm{c}}$ \\
$\mathrm{S}_{4}$ & $7.30^{\mathrm{d}}$ & $7.10^{\mathrm{d}}$ & $7.20^{\mathrm{b}}$ & $7.10^{\mathrm{d}}$ \\
$\mathrm{S}_{5}$ & $8.70^{\mathrm{a}}$ & $8.20^{\mathrm{a}}$ & $8.40^{\mathrm{a}}$ & $8.30^{\mathrm{b}}$ \\
$\mathrm{S}_{6}$ & $7.50^{\mathrm{d}}$ & $7.30^{\mathrm{cd}}$ & $7.30^{\mathrm{b}}$ & $7.50^{\mathrm{cd}}$ \\
$\mathrm{S}_{7}$ & $8.40^{\mathrm{ab}}$ & $8.30^{\mathrm{a}}$ & $8.70^{\mathrm{a}}$ & $8.80^{\mathrm{a}}$ \\
$\mathrm{S}_{8}$ & $8.00^{\mathrm{bc}}$ & $7.90^{\mathrm{ab}}$ & $7.70^{\mathrm{b}}$ & $7.80^{\mathrm{c}}$ \\
\hline
\end{tabular}

Mean with same superscript within a column are not significantly different at $5 \%$ level of significance

All samples are ranked as "like moderately". Sample $S_{1}$ and $S_{2}$ secured score of 4.8 and 4.3, respectively, and can be ranked as "dislike slightly".

In case of flavour, there were significant differences in acceptance of flavour among the samples at $5 \%$ level of significance as calculated probability value was less than 0.05 . As shown in the Table 5, samples $\mathrm{S}_{7}$ and $\mathrm{S}_{5}$ were most acceptable in flavour preference among the samples securing the highest score of 8.3 and 8.2 , respectively and were ranked as "like very much". This was followed by the samples $\mathrm{S}_{3}, \mathrm{~S}_{4}$, $\mathrm{S}_{6}$ and $\mathrm{S}_{8}$ securing 7.7, 7.1, 7.3 and 7.9, respectively and were equally acceptable which ranked as "like moderately". The sample $S_{1}$ securing 5.4 ranked as "neither like nor dislike" and $\mathrm{S}_{2}$ securing 4.7 ranked as "dislike slightly". Table 5 showes that there were significant differences in texture acceptance among the samples at $5 \%$ level of significance as calculated probability value was less than 0.05 .

As shown in Table 5, samples $S_{7}$ and $S_{5}$ were most acceptable in texture preference among the samples securing the highest score of 8.7 and 8.4 , respectively and were ranked as "like very much". This was followed by the samples $\mathrm{S}_{3}, \mathrm{~S}_{4}$, $\mathrm{S}_{6}$ and $\mathrm{S}_{8}$ securing 7.7, 7.2, 7.3 and 7.7, respectively and were equally acceptable which ranked as "like moderately". The samples $S_{1}$ and
$\mathrm{S}_{2}$ secured scores of 5.4 and 5.2, respectively and were ranked as "neither like nor dislike".

In case of overall acceptability, there were significant differences in overall acceptability acceptance among the samples at 5\% level of significance. $\mathrm{S}_{7}$ was most acceptable in overall acceptability preference among the samples securing the highest score of 8.8 and was ranked as "like very much". This was followed by the sample $\mathrm{S}_{5}$ and also ranked as "like very much". The samples $\mathrm{S}_{3}, \mathrm{~S}_{4}$, S6 and $\mathrm{S}_{8}$ securing 7.7, 7.1, 7.5 and 7.8 , respectively were equally acceptable and were ranked as "like moderately". The samples $S_{1}$ and $S_{2}$ secured score of 5.7 and 5.0, respectively and were ranked as "neither like nor dislike".

From the above results it is clearly observed that the sample $S_{7}(0.5 \mathrm{~cm}$ slice, osmosed in $60 \%$ sugar solution $)$ and $S_{5}(0.5 \mathrm{~cm}$ slice, osmosed in $50 \%$ sugar solution) were the most preferred sample with respect to all quality attributes and were ranked as "like very much". However, $S_{7}$ was the most acceptable among them.

\section{Conclusions}

Good quality pineapple candy with high overall acceptability may be processed by osmotic dehydration followed by conventional dehydration (solar drying) with shelf-life of six months at ambient temperature condition. 


\section{References}

Clydesdale, F. M. 1984. The influence of colour on sensory perception and food choice. In: Developments in Food Colours - 2. J. Walford (Ed.), Elsevier Applied Science Publishers, London, 75-112 pp.

Clydesdale, F. M. 1991. Colour perception and food quality. J. Food Quality. 14: 61-74.

Clydesdale, F. M. 1993. Colour as a factor in food choice. CRC Crit. Rev. Food Sci. Nutrition, 33(1): 83-101.

Contreras, J. E. and T. G. Smyrl. 1981. An evaluation of osmotic concentration of apple rings using com syrup solids solutions. Can. Inst. Food Sci. Technol. J., 14 (4): 310-314.

Hawakes, J. and J. M. Flink. 1978. Osmotic concentration of fruit slices prior to freeze-dehydration. J. Food Processing and Preservation, 2: 265-284.

Heng, K., S. Guilbert and J. L. Cuq. 1990. Osmotic dehydration of papaya: influence of process variables on the product quality. Sciences desAliments, 10: 831-848.

Kim, M. H. and R. T. Toledo. 1987. Effect of osmotic dehydration and high temperature fluidized bed drying on properties of dehydrated rebbiteye blueberries. J. Food Science, 52: 980-989.

Shahabuddin, M., Hawlader, M. N. A and M. S. Rahman. 1990. Evaluation of drying characteristics of pineapple in the production of pineapple powder. J. Food processing and preservation, 14: 375-391.

Lenart, A. and J. M. Flink.1984. Osmotic concentration of potato. I. Criteria for the end-point of the osmotic process. J. Food Technology, 19: 45-63.

Ramamurthy, M. S., Bongiwar, D. R. and Bondyapadhayay, D. (1970). Osmotic dehydration of fruits, possible alternative to freeze drying. Indian Food Packer, 32(1): 108-111. 